\title{
Uso do Custom-Made Based Costing-CBC no Custeamento das Características de Produtos e Serviços
}

\author{
Fabrícia Silva da Rosa \\ E-mail: fabriciasrosa@hotmail.com \\ Rogério João Lunkes \\ E-mail: lunkes@cse.ufsc.br
}

\section{RESUMO}

As mudanças que afetam o mundo empresarial têm levado as empresas a inovar seus processos de negócio, decorrente da necessidade de atender as expectativas dos clientes, levando muitas a customizar ou personalizar seus produtos e serviços. Essa nova tendência traz dificuldades às práticas atuais, principalmente no custeamento, isto porque esses produtos e serviços demandam recursos diferenciados. O presente estudo tem como objetivo apresentar a sistemática de gerenciamento dos custos por meio das características, identificando as variações e custos decorrentes. Para tanto, a pesquisa aborda o custeio e o gerenciamento baseado em características. E o método utilizado foi uma pesquisa exploratória pelo fato do tema ser pouco conhecido e, o procedimento adotado na condução do trabalho é o bibliográfico/documental. Os resultados obtidos indicam que o sistema tem grande potencial em empresas inseridas em mercados com produtos e serviços customizados e personalizados. As informações decorrentes dessa sistemática permitem identificar características que agregam ou não valor, minimizar seus custos, otimizar o processo de produção, desenvolver produtos e serviços mais adaptáveis as necessidades dos clientes e permite melhor formação do seu preço de venda.

Palavras chave: Custom-Made Based Costing. Gerenciamento e características.

\section{The Use of Custom-Made Based Costing-CBC in Costing of the Features of Products and Services}

\begin{abstract}
The changes that affect the business world nowadays have led the enterprises to innovate their business procedures, with the objective of satisfying their clients' expectations, and many have decided to personify their products and services. This new trend has brought some difficulties to the present practices, mainly in what concerns costing, because those products and services demand different resources. The present study aims at presenting a system of costing management through characteristics, identifying their variations and resulting costs. Thus the present research deals with custom-made based costing and management. The method adopted was the
\end{abstract}


exploratory research since the topic is not well-known yet and the procedures followed included the bibliographical research. The results show that the system offers good perspectives for enterprises which offer personified products and services. The information triggered by the system allows one to identify the characteristics that aggregate new value and those that do not; it also leads to a decrease in costs and an upgrade in the production process, leading to the development of products and services more adequate to the clients' needs besides allowing the establishment of their selling prices.

Keywords: Custom-Made Based Costing. Management. Characteristics.

\section{INTRODUÇÃO}

As condições da atividade empresarial estão em constantes mudanças. MacRae (1999) descreve que são cinco as principais forças que estão redesenhando o mundo: a mudança da estrutura demográfica, o avanço tecnológico, o processo de globalização, a preocupação com o meio ambiente e o impacto das mudanças governamentais sobre a sociedade. Quanto às empresas, elas terão o futuro definido por seu capital intelectual, uma nova estrutura influenciada pela tecnologia e clientes bem diferentes.

Chimerine (1997) acredita que estas mudanças não costumam ser, por natureza, cíclicas ou de curto prazo. Muitas das mudanças alteram para sempre o contexto econômico mundial. Esta visão é corroborada por Fuller (1999) quando descreve que, independentemente de setor, de empresa, de nacionalidade, há sempre um competidor pronto para a batalha. As empresas precisam aprender a lutar nesta nova era e a ela adaptar sua estratégia e suas operações.

A globalização e o avanço tecnológico exercem constante pressão sobre as empresas pela oferta de produtos com características diferenciadas, exigindo respostas rápidas e concretas, com 0 desenvolvimento de projetos que contemplem as expectativas dos consumidores. Assim, as empresas eficientes em trazer com rapidez produtos e serviços de maior valor agregado para o mercado conseguem obter vantagem competitiva.

Diante disso, percebe-se que o grande desafio na atual conjuntura parece ser o acompanhamento do avanço extraordinário das novas tecnologias. Estas podem estar 
relacionadas a áreas específicas do processo produtivo, comercialização, atendimento ao cliente, entre outros. Seybold (2002) acredita que as novas tecnologias permitem colocar em curso as verdadeiras mudanças. Segundo o autor, utilizando a Internet e aos dispositivos sem fio, os clientes têm ferramentas novas para entrar em contato com as empresas e com os concorrentes, a qualquer momento e lugar do mundo. $E$ mais ainda: começam a exigir que as empresas modifiquem as estruturas de preços, os canais de distribuição e a maneira como projetam e entregam produtos e serviços.

Por meio da Internet, os consumidores podem encontrar qualquer item que desejam e, ao preço mais adequado. As empresas, de sua parte, devem utilizar a Internet para alcançar múltiplos segmentos de clientes e oferecer novos produtos, concebidos especialmente para eles, além de inovar e experimentar mais rapidamente do que nunca. Na realidade, empresas que oferecem experiências de alta qualidade a seus clientes não precisam esperar por relatórios mensais: elas dispõem de alertas em tempo real cada vez que um cliente não consegue satisfazer suas expectativas. Agora, as empresas de sucesso são aquelas que, de forma consistente, atendem e excedem as expectativas dos consumidores cada vez mais bem informados.

Por conseguinte, as mudanças decorrentes da comercialização atingem os processos, produtos e serviços. Segundo Sakurai (1997), a automação exerce influencias significativas na maneira de administrar as operações e possibilita maior flexibilidade com os sistemas integrados na busca de eficiência operacional necessária para implantação de uma estratégia avançada de gestão, ligando marketing, engenharia, produção e demais áreas.

Assim, a tecnologia e os processos transformam a base para criação da arquitetura da Internet, ou seja, permite encarar o consumidor em tempo real. Além disso, a logística da tecnologia e dos processos permite adaptar e personalizar os produtos, quer se trate de computadores ou calça jeans (RAPP, 1999). Isto abre possibilidade de inovar a estratégia de marketing de "um-a-um" para "muitos-paraum", dispondo aos consumidores muitos prospectos a sua escolha.

Desta forma, os clientes estão cada vez mais dispostos a personalizar seus produtos ou serviços. Diante dessa tendência, as empresas, encontram dificuldades na 
O Uso do Custom-Made Based Costing-CBC no Custeamento das Características de Produtos e Serviços

Fabrícia Silva da Rosa, Rogério João Lunkes

determinação do custo final de cada produto ou serviço. Isto ocorre porque esses produtos ou serviços, em decorrência de variações e complexidade, demanda recursos diferenciados. $\mathrm{O}$ artigo aborda uma forma de custeamento, que vem de encontro a essa necessidade, denominado Custom-Made Based Costing.

\section{NECESSIDADE DO CUSTOM-MADE BASED COSTING - CBC}

Diante do exposto anteriormente, as empresas precisam reconhecer o impacto crescente da personalização dos produtos e serviços na satisfação dos clientes. Esses clientes pedem frequentemente um nível de customização do produto que os sistemas tradicionais não podem satisfazer. Estes clientes, que são geralmente os mais lucrativos, demandam um alto nível de seletividade e flexibilidade. Isto conduz naturalmente à idéia de permitir que eles criam seus próprios produtos e serviços.

Não obstante, é percebível que, pressionadas pela concorrência e exigência dos consumidores, as empresas em geral passaram a produzir grande variedade e pequenas quantidades de produtos com características diferenciadas. A mudança de postura do consumidor e do mercado exige mudanças no processo de produção, tornando-o mais flexível e levando-o a funcionar numa estrutura organizacional horizontal e num ambiente totalmente automatizado, que utiliza tecnologia de última geração.

Essa sistemática é conhecida como customização em massa (Mass Customization) e personalização (Personalization). Para Tseng e Piller (2003), esses termos não podem ser confundidos, enquanto customização relaciona a mudança ao ajuste ou a modificação do produto ou serviço de acordo com a necessidade e o desejo dos clientes; a personalização envolve intensa comunicação e interação entre as duas partes, isto é, o cliente e fornecedor.

Nesse contexto, de acordo com Shank (2000), os sistemas de custos agora precisam partir do mercado e ir retrocedendo até chegar á empresa. No entanto, essa semântica pode gerar inúmeros problemas relacionados ao custeamento do produto ou 
serviço. Isto ocorre porque muitas delas não são capazes de produzir pequenos pedidos a um custo razoável.

Então, percebe-se que o principal desafio para empresas que adotam uma abordagem de produto customizado ou personalizado é administrar as várias combinações e variações que o produto pode ter. Para ilustrar melhor essa problemática utilizamos a venda de camisas personalizadas pela Internet. Conforme figura 1, o cliente pode optar por diferentes características como, social e esporte, tipo de tecido, cores e padrões, colarinho e manga e tamanho, entre outras. Nesse exemplo de personalização, a Closet produz camisas de diferentes tamanhos adaptados ao gosto do cliente.
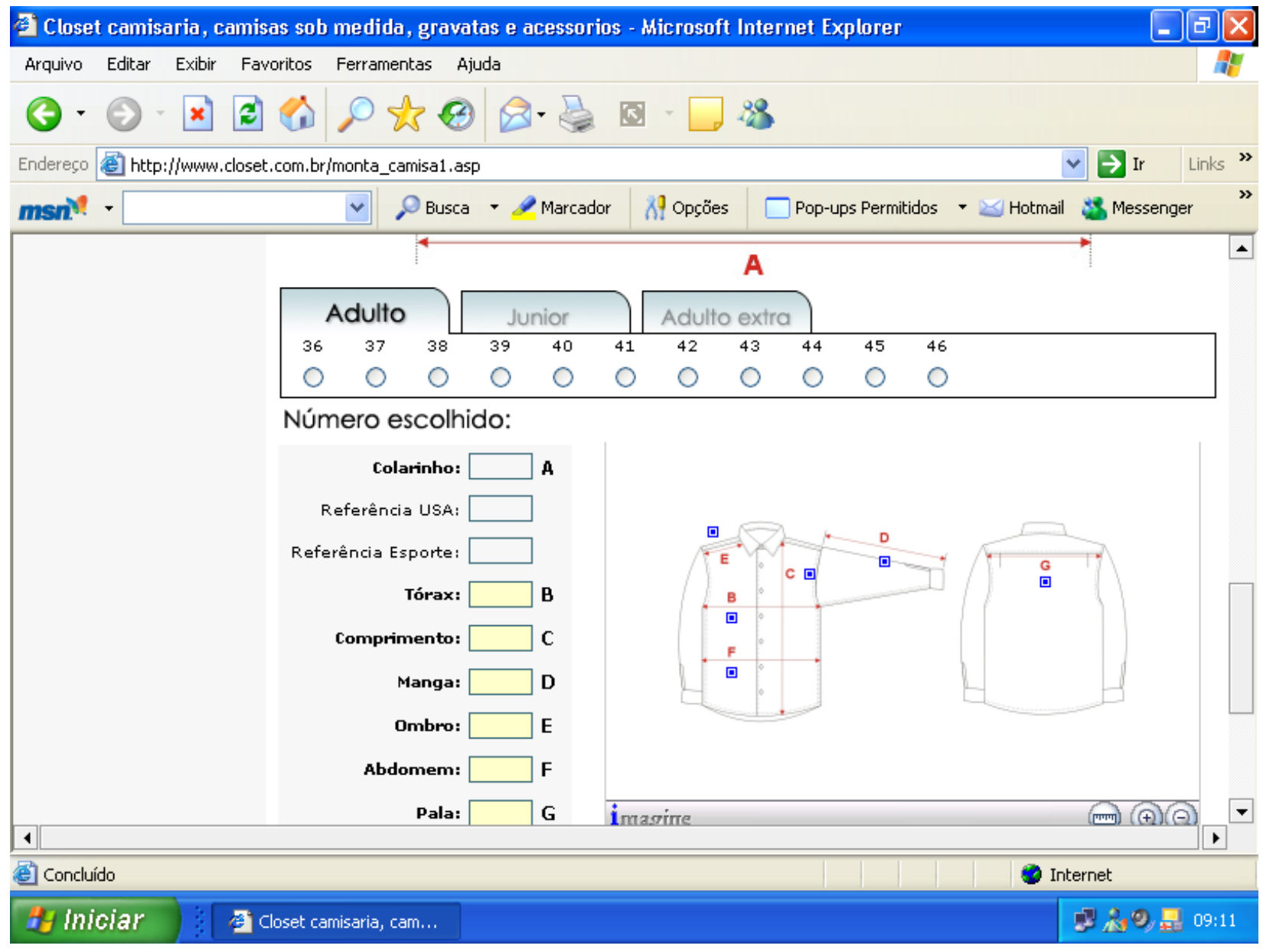

Figura 1 - Exemplo de venda de produto personalizado

Fonte: Closet, 2005 (www.closet.com.br) 
Sendo assim, esse desejo do cliente gera nas empresas problemas de custeamento, em razão dos métodos de custeio determinar o custo do produto e não da característica. Há uma necessidade de maior detalhamento dos custos dos produtos em virtude da formação do preço das características. Tal problemática é reforçada por Zimmerman (2000), quando descrevem que $70 \%$ dos negócios nos Estados Unidos da América formam o preço de venda baseado no custo. O preço é um elemento importante na decisão de compra do consumidor, portanto, ele é parte do poder de competitividade da empresa. Para praticar preços competitivos, obrigatoriamente é necessário conhecer, minimizar e controlar os custos.

Geralmente, os processos industriais apresentam limitações na determinação dos custos das características. Portanto, há a necessidade de um sistema que proporcione a empresa, a determinação do custo dessas diferentes especificações, caso contrário, haverá características sub-custeadas e outras sobre-custeadas.

Para ilustrar tal fato, imagine que você e seus colegas de trabalho vão para um bar após o expediente. Você faz o pedido de uma porção de batata frita e refrigerante, enquanto os demais pedem uma rodada de camarão com vinho importado. Quando o garçom traz a conta, eles pedem para dividir igualmente. Como você se sentiria? Isto acontece em muitas empresas que fabricam produtos e serviços customizados ou personalizados. Da mesma forma que a conta, elas rateiam seus custos igualmente aos produtos ou serviços, fazendo com que um produto (cliente) pague pelo custo que o outro consumiu.

Aliado a isto, os gerentes operacionais frequentemente afirmam que o design do produto é o direcionador de custo mais importante. Eles apontam o número de etapas do processo, a complexidade do produto e os tipos de partes e volumes como fatores além do controle (TURNEY, 1993). Para gerenciar esses fatores no atual estágio de gestão é necessário possuir informações sobre os custos das características na fase de projeto e desenvolvimento do produto.

É nesta fase que muitos dos problemas relacionados a custos pode ser corrigida. $\mathrm{Na}$ realidade, a oportunidade para redução de custos por meio do design do produto e processo é ilimitada. Uma percentagem grande do custo do produto ou custo do ciclo 
de vida, segundo pesquisas, aproximadamente $60-80 \%$ é determinado por decisões tomadas na fase de concepção e desenvolvimento.

Diante dos problemas apresentados, somente a utilização de um sistema de gestão estratégica de custos, resulta em custo das características mais preciso. De modo que, quanto mais evoluímos para a customização em massa e personalização, mais necessitamos adotar sistemas de custeio visando assegurar que essa sistemática esteja gerando lucro à empresa. Em tais situações, os gestores precisam considerar um novo sistema de gerenciamento dos custos. Este sistema é denominado de CustomMade Based Costing.

\section{CONCEITOS E DEFINIÇÕES}

O CBC é uma metodologia de gestão estratégica dos custos, aliada as necessidades e desejos dos consumidores. Esse sistema baseia-se no custeamento dos objetos de custo por meio de suas características, permitindo com isso, o seu cálculo e projeção. Assim, a ideia central é definir o custo das características na fase de desenvolvimento do produto, serviço, cliente, processo ou família de produtos, auxiliando as empresas na customização em massa ou personalização.

É uma ferramenta que permite melhorar a visualização dos custos das características e, seu impacto sobre o custo total dos objetos, decorrente da complexidade de sua execução. No CBC as atenções estão voltadas aos custos das características, tendo em vista a evolução do mercado com a customização e personalização. As características permitem o cálculo do custo diferenciado para cada produto ou serviço.

Essas informações sobre as características podem ser rapidamente e facilmente atualizadas com as mudanças no processo. Adicionalmente, novos produtos podem ser facilmente custeados quando apresentam características semelhantes e; novas características podem ser identificadas e acrescentadas ao novo objeto de custo.

$\mathrm{O} C \mathrm{CBC}$ direciona os recursos e custos das atividades às características e, destas aos objetos de custo, conforme figura 2. 


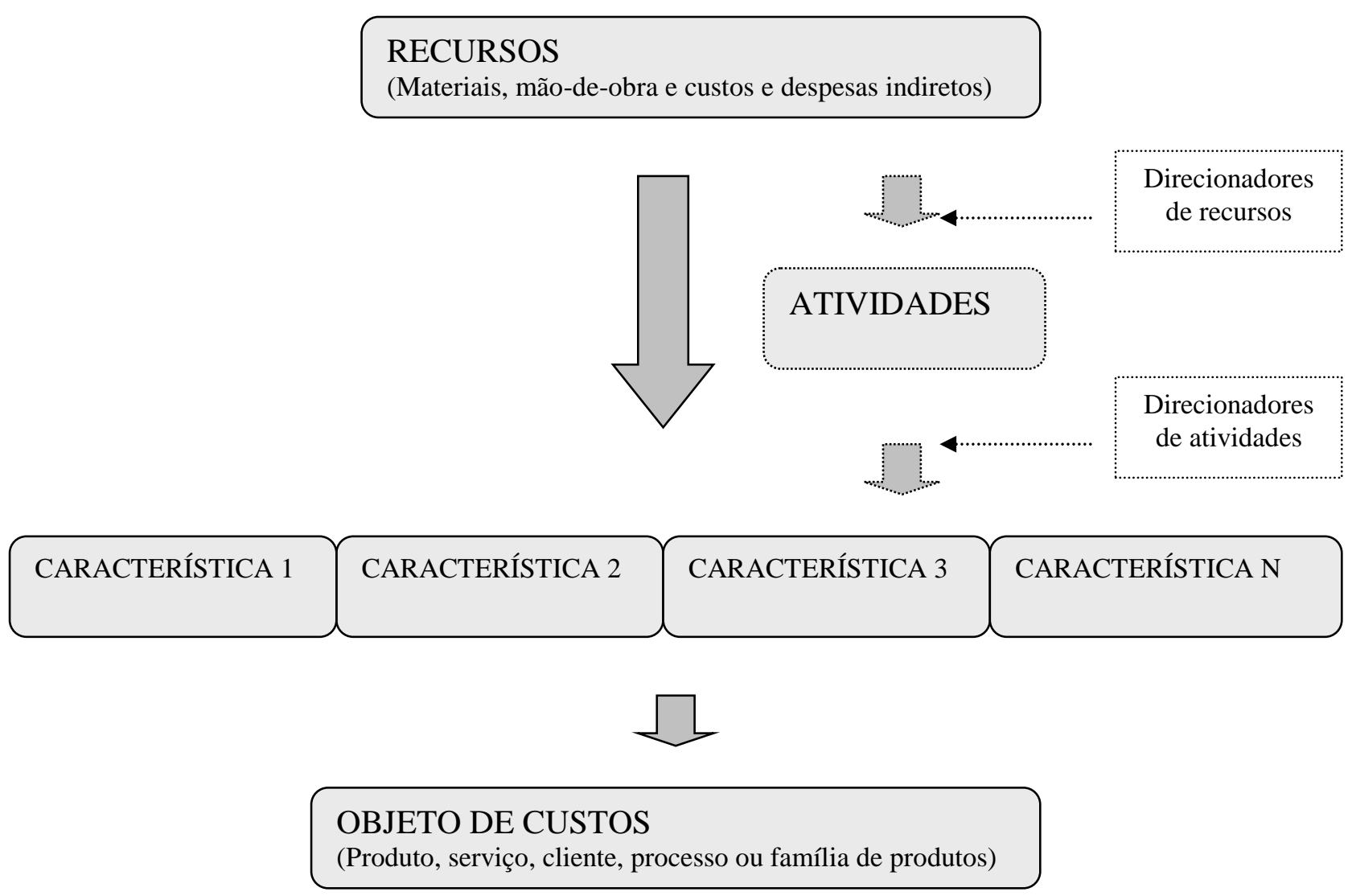

Figura 2 - Visão geral do custom-made based costing

É recomendável ao adotar essa estratégia dividir o objeto de custos em características, visando expandir seu conceito e criar novas combinações e, consequentemente, administrar a complexidade. Assim, além de gerenciar os custos em nível de desenvolvimento e produção e suas respectivas atividades, possibilita aos gestores adotarem uma posição pró-ativa para sua prevenção e eliminação, constituindo-se num fator determinante para as empresas competirem com melhores atributos de valor.

\subsection{Conceitos Básicos}

Para melhor entendimento do CBC alguns conceitos são definidos na sequência.

Os recursos são os insumos (input) consumidos no processo visando à geração de bens e serviços (output). 
O direcionador de custo é qualquer fator ou atividade que têm uma relação de causa-efeito direto com o consumo dos recursos. O direcionador de custo pode ser dividido em direcionador de recursos, quando aloca recursos às atividades e; direcionador de atividade, quando aloca custos das atividades às características.

A atividade é qualquer evento, ação, transação ou trabalho que a empresa incorre para produzir um produto ou prestar um serviço. As atividades são necessárias para a concretização de um processo, que é uma cadeia de atividades correlatas, interrelacionadas. Exemplo: comprar matérias, atender os clientes, emitir as faturas, receber os valores, montar, pintar, embalar etc.

No conceito amplo, segundo o Dicionário Aurélio, característica é aquilo que distingue uma coisa da outra. No modelo, a definição de característica restringe-se a qualquer evento que causa na organização tarefas adicionais ou altera a forma de executar o processo. Uma característica pode então ser definida como um fator, evento que causa uma variação no processo de produção do objeto de custo.

O quadro 1 ilustra alguns exemplos de tipos de características que as empresas podem utilizar no desenvolvimento do CBC.

\begin{tabular}{|c|c|}
\hline Tipos de Características & Exemplos \\
\hline Geométrico & Comprimento, largura, profundidade, perímetro, volume, área. \\
\hline Atributos & Tolerância, fim, densidade, massa, material, composição. \\
\hline Físico & Buraco, bolso, pele, tábua de PC, cabo, mastro, asa. \\
\hline Processo & Compras, vendas, produção, recursos humanos, finanças etc. \\
\hline Montagem & Interconecte, insira, alinhe, junte, prenda. \\
\hline Atividades & Pesquisar e desenvolver, montar, pintar, embalar e controlar etc. \\
\hline
\end{tabular}

Quadro 1 - Exemplos de diferentes características

O quadro 1 apresenta um nível de definição de características; porém, há vários níveis de definições de características. Por exemplo, a característica de uma aeronave pode ser a asa, contudo a asa contém muitas partes, cada uma pode ser dividida em mais.

objeto de custo são as saídas do processo que a empresa deseja custear, como: produto, serviço, cliente, processo, família de produtos, eventos, idéias, entre outros. 
O Uso do Custom-Made Based Costing-CBC no Custeamento das Características de Produtos e Serviços

Fabrícia Silva da Rosa, Rogério João Lunkes

\subsection{Principais Atributos do CBC}

De acordo com a figura 2, vamos agora destacar alguns atributos determinantes deste modelo:

- a matéria-prima e mão-de-obra direta têm por sua própria natureza, uma base direta de alocação às características;

- apresenta características e atividades como centro de alocação dos custos, para posteriormente determinar o custo dos objetos;

- considera como premissa o custo dos objetos aqueles que iniciam com o desenvolvimento até o pós-venda;

- sua efetivação necessita da participação de inúmeras funções, cujo trabalho está relacionado com vários objetos;

- fundamenta-se na definição de características consideradas fundamentais na visão do cliente e, considera para efeitos de cálculo aquelas características e atividades que agregam valor ao objeto;

- requer para seu funcionamento, uma forte etapa de estudos, que objetivam definir as características, atividades e sua relação com os diferentes objetos, que visam racionalização de processos por meio do planejamento.

\section{ETAPAS NO DESENVOLVIMENTO DO CUSTOM-MADE BASED COSTING}

Antes de implantar o CBC, deve-se preparar o ambiente para ter sucesso no seu desenvolvimento. Geralmente, as empresas falham na implantação de ferramentas como o CBC por envolver concepção incorreta sobre o que o sistema requer. Para tanto, o trabalho sugere o desenvolvimento do CBC em nove etapas (passos), que são: 


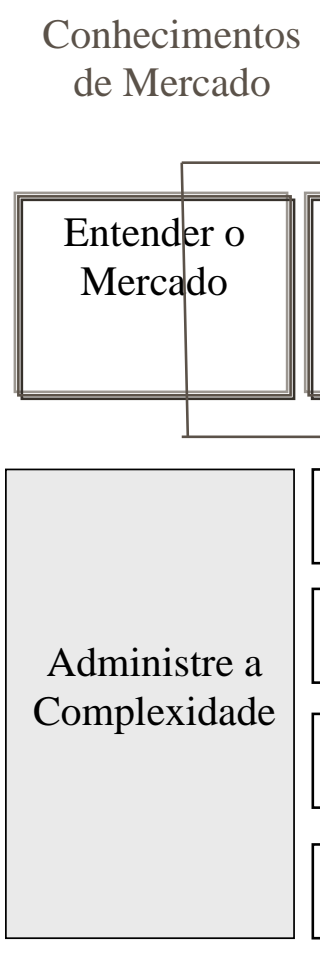

Desmembrar

o Objeto

Dividir o

Objeto em

Partes Distintas

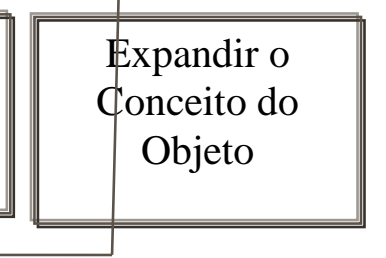

Desenvolvimento do

Modelo Conceitual

\begin{tabular}{|c||l||}
\hline \hline Criar Novas & Identificar \\
Combinações & Atividades \\
& Associadas \\
\hline \hline
\end{tabular}

Associe Características e Perfis dos Objetos

Determine o Custo da Atividade

Identifique as Características que Causam Variação

Determine o Custo da Característica

Figura 3 - Etapas no desenvolvimento do CBC

\section{Etapa 1: Entender o Mercado}

No primeiro momento precisa-se entender bem o mercado consumidor com suas necessidades e demandas. Assim, atributos de valor como: preço, custo, qualidade, tempo e inovação podem ser projetados para atender o consumidor em suas necessidades específicas. De acordo com esse pensamento, não visualiza-se um mercado, mas sim, clientes individuais; para tanto, necessitamos de informações significativas sobre suas expectativas.

Portanto, a realização de pesquisas em massa utilizando a sistemática tradicional não gera os resultados esperados. Nesse caso, é preciso utilizar novas metodologias e ferramentas de pesquisa, para identificar as aspirações dos consumidores. O uso da tecnologia, particularmente a Internet, pode ser interessante para criar um relacionamento absolutamente pessoal. 
O Uso do Custom-Made Based Costing-CBC no Custeamento das Características de Produtos e Serviços

Fabrícia Silva da Rosa, Rogério João Lunkes

\section{Etapa 2: Dividir o Objeto em Partes Distintas}

Diante das informações coletadas pode-se identificar as características relacionadas às aspirações individuais dos consumidores. Para identificá-las é necessário dividir o objeto em partes e relacionar quais delas geram experiência única, portanto, este desdobramento é realizado ao nível que a empresa considera não mais haver variação no processo. Nesse sistema, a característica é um elemento principal que será custeado.

Com o objeto desmembrado em características, há muito mais possibilidade de atender melhor às expectativas dos clientes.

A característica principal de uma camisa, por exemplo, pode ser o estilo, tecido, cores e padrão, colarinho, tamanho e comprimento das mangas etc. Para entender melhor as diferentes características observe a figura 4.

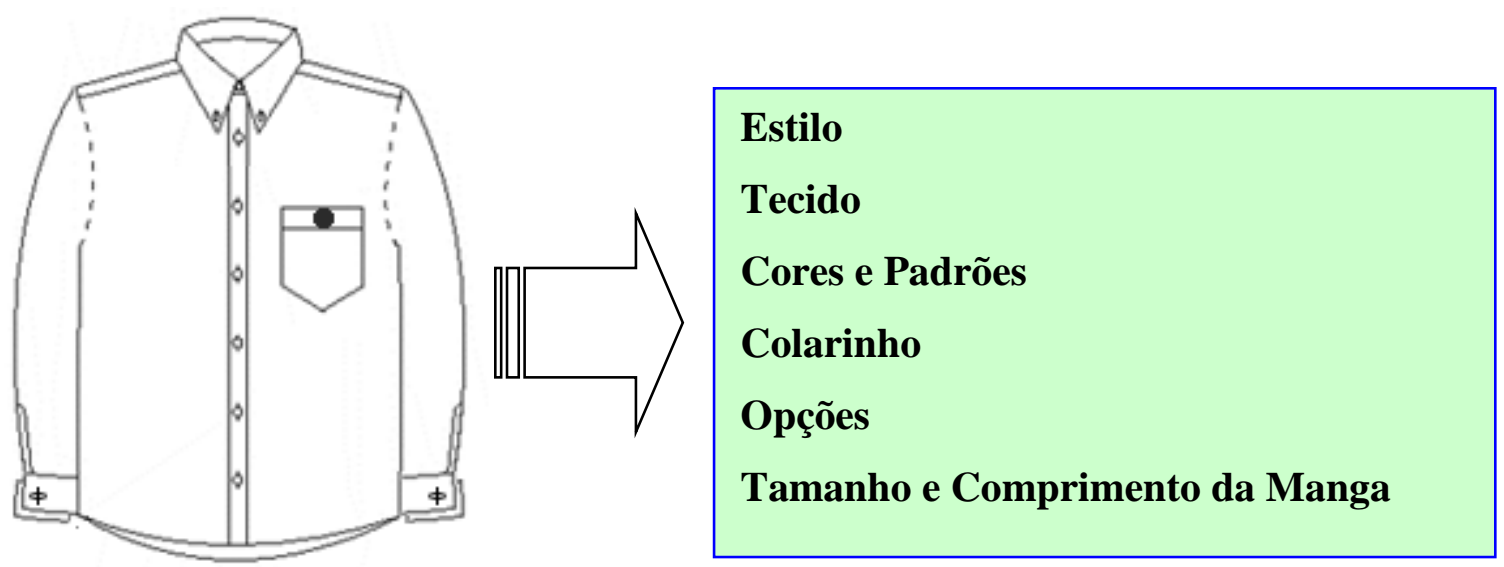

Figura 4 - Exemplo de produto e suas características

As características da figura 4 podem ser divididas em outras, como por exemplo, o estilo em social e esporte. Assim, cada negócio apresenta suas próprias características em relação a seu objeto. O que pode ser uma característica para uma empresa não necessariamente será em outra. 
O Uso do Custom-Made Based Costing-CBC no Custeamento das Características de Produtos e Serviços

Fabrícia Silva da Rosa, Rogério João Lunkes

\section{Etapa 3: Expandir o Conceito do Objeto}

$\mathrm{Na}$ projeção do objeto básico deve-se considerar a possibilidade de aperfeiçoamentos e expansão do conceito. Com essa base, a empresa, pode agregar valor com novas características e assim gerar um relacionamento de longo prazo com o cliente. É extremamente importante agregar valor ao objeto básico por meio de opções de serviço.

\section{Etapa 4: Criar Novas Combinações}

Nessa etapa a empresa cria um conjunto de novas combinações visando satisfazer as expectativas dos clientes. A criatividade e a inovação são importantes para projetar soluções as diferentes necessidades.

Por exemplo, as montadoras de automóveis tornaram mestres em projetar carros flexíveis, desta forma, a partir de uma base (chassis) é possível produzir inúmeros modelos diferentes atendendo a todos os gostos.

As empresas por meio de pesquisa podem fazer com que os clientes mostrem o caminho para as novas combinações dos objetos. O grande desafio nesse momento é oferecer combinações que possam aumentar a percepção de valor do cliente. Neste caso, as informações sobre as expectativas de mercado e a estratégia corporativa são combinadas para possibilitar a oferta de objetos customizados em massa ou personalizados.

\section{Etapa 5: Identificar Atividades Associadas com Cada Característica}

Essa etapa envolve inicialmente a identificação das atividades empreendidas na execução da característica. Em seguida, são definidos também os direcionadores de custos, que são os fatores que causam mudança na execução da atividade e, apontando os respectivos recursos consumidos. Os passos de elaboração são as atividades necessárias para fabricar a característica do objeto. 


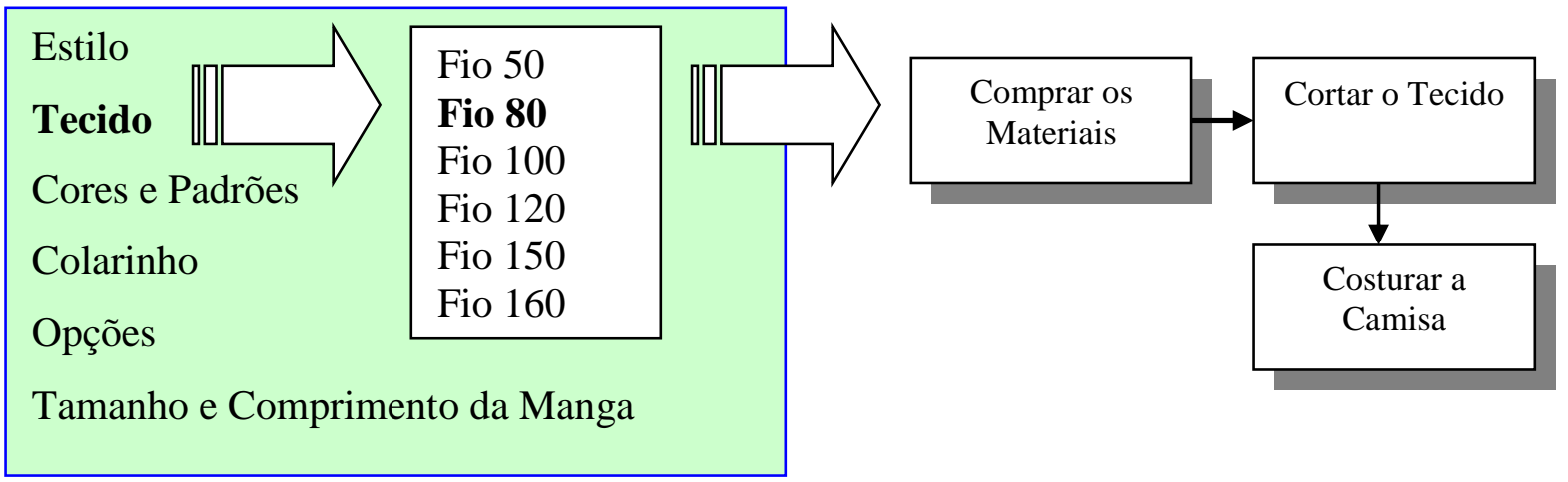

Figura 5 - Exemplo de atividades envolvidas na execução da característica

Cada característica tem seu próprio processo de execução, podendo englobar diferentes atividades. Nessa etapa, é importante diferenciar as atividades relacionadas a cada característica, de modo que possam ser utilizadas e integradas diminuindo sensivelmente o grau de complexidade. Isto ajuda no compartilhamento das características pelas atividades-padrão, redução do número de componentes e tempo de ciclo.

\section{Etapa 6: Associe Características e Perfis dos Objetos}

Nessa etapa as características que foram determinadas nas etapas 1 e 4 são associadas ao objeto.

\begin{tabular}{|l|l|l|}
\hline $\begin{array}{c}\text { Características principais do } \\
\text { objeto }\end{array}$ & Sub-categorias do objeto & \multicolumn{1}{c|}{ Rotinas } \\
\hline - Estilo & - Fio 50 & Receber o pedido \\
- Tecido & - Fio 80 \\
- Cores e Pad & - Fio 100 \\
- Colarinho & - Fio 120 \\
- Opções & - Fio 150 \\
- Tamanho e Mangas & - Fio 160 & \\
\hline
\end{tabular}

Quadro 3 - Exemplo de sub-categorias do objeto e rotinas

A empresa pode construir rotinas e procedimentos para as características. Nessa etapa é importante determinar as condições ideais de produção, bem como, a 
O Uso do Custom-Made Based Costing-CBC no Custeamento das Características de Produtos e Serviços

Fabrícia Silva da Rosa, Rogério João Lunkes

capacidade do processo e os fatores das perdas. Portanto, é essencial gerenciar dois aspectos simultaneamente: o posicionamento estratégico e a redução dos custos.

\section{Etapa 7: Determinar o Custo de Cada Atividade}

Nessa etapa é mensurado o custo de cada atividade definida anteriormente. $\mathrm{O}$ custo da atividade pode consistir de pessoas, máquinas, viagem, materiais, sistemas de informação etc. Também durante essa etapa, o custo das atividades secundárias são direcionadas a(s) atividade(s) principal(is) para determinar o custo final de cada atividade. Esse custo da atividade principal será usado para determinar o custo da(s) característica(s) e, consequentemente, do objeto.

Tabela 1 - Custo da atividade de costurar a camisa com fio 80

\begin{tabular}{|c|c|c|c|}
\hline Recursos & Direcionadores & Custo & Custo Total - R\$ \\
\hline Costureiro & 0,30 minutos & $\mathrm{R} \$ 20 /$ hora & 6,00 \\
\hline $\begin{array}{c}\text { Materiais (Tecido, linha } \\
\text { etc) }\end{array}$ & 1,5 & $\mathrm{R} \$ 30 /$ litro & 45,00 \\
\hline $\begin{array}{c}\text { Equipamentos } \\
\text { (Depreciação) }\end{array}$ & $0,30^{*}$ minutos & $\mathrm{R} \$ 2.08$ & 0,62 \\
\hline Total da Atividade & & & $\mathbf{5 1 , 6 2}$ \\
\hline
\end{tabular}

* $20.000 / 9600=2.08$

Para determinar o custo da atividade pode-se utilizar uma tarefa ou característica padrão. Por exemplo, costurar a camisa com o fio 80 .

\section{Etapa 8: Identificar as Características do Objeto que Causam a Variação no Processo}

Nessa etapa são determinadas as características que causam variação na produção do objeto. Uma característica pode distinguir um objeto do outro. No exemplo da camisa, algumas características do produto seriam o estilo, tecido, as cores e padrões, o colarinho etc. Com a determinação dessas características do objeto pode-se prever a variação do processo como, por exemplo, trabalho adicional, tempo de processamento, problemas de qualidade, entre outros. 
O Uso do Custom-Made Based Costing-CBC no Custeamento das Características de Produtos e Serviços

Fabrícia Silva da Rosa, Rogério João Lunkes

\begin{tabular}{|c|c|c|c|c|}
\hline Estilo & Tecido & Cores e Padrões & Colarinho & Opções (Punho) \\
\hline Social & Fio 50 & Vista Lisa & Francês & Punho 1 \\
\hline Esporte & Fio 80 & Vista Coberta & Inglês & Punho 2 \\
\hline & Fio 100 & Vista Militar & Italiano & Punho 3 \\
\hline & Fio 120 & & Suíço & Punho 4 \\
\hline
\end{tabular}

Quadro 4 - Exemplo das principais características da camisa

A partir da definição das características do produto na etapa 4 (quatro), vamos determinar a causa da variação do processo. Se as características do produto causam uma perda ao processo, é necessário determinar o valor e, o que isto acrescentará ao custo final do objeto específico.

É importante compatibilizar, além das atividades, também hardware e software, imagens, marcas, reutilizando os ativos com base em combinações múltiplas de características. Assim, a empresa estará gerenciando as várias combinações e variações decorrentes da flexibilidade do objeto.

As características são identificadas pelo grau de dificuldade de execução. Assim, o custo da característica "tecido" pode variar em razão da complexidade, o que demanda mais tempo para realizá-la. Por exemplo, a espessura do tecido "fio 160" pode necessitar de mais tempo e máquinas especiais para sua execução.

\section{Etapa 9: Determinar o Custo da Característica}

$\mathrm{Na}$ etapa final é computado o custo das características para determinar o custo do objeto. Todos os custos das etapas anteriores são calculados e somados para determinar o custo final do objeto contendo aquelas características específicas.

Tabela 3 - Exemplo de custo da característica

\begin{tabular}{|c|c|}
\hline Característica do Produto & Custo da Característica \\
\hline$\bullet$ Fio 50 & $\mathrm{R} \$ 38,00$ \\
\hline$\bullet$ Fio 80 & $\mathrm{R} \$ 51,62$ \\
\hline - Fio 100 & $\mathrm{R} \$ 63,25$ \\
\hline
\end{tabular}

O exemplo procura ilustrar as diferentes formas de como esse processo pode ser desenvolvido. O CBC apresenta inúmeras vantagens, que são descritas no item a seguir. 


\section{VANTAGENS DO CBC}

O CBC apresenta inúmeras vantagens em relação aos sistemas convencionais na determinação do custo das características e do objeto. Esse modelo permite entender melhor o custo das características do objeto, auxiliando na gestão dos custos e do processo.

Há várias razões para examinar o uso de características como uma base de custeamento durante a fase de desenvolvimento e produção. Os objetos podem ser descritos essencialmente como uma associação de várias características. Por exemplo, a camisa é formada a partir de diferentes características como, estilo, tecido, cores e padrões, colarinho, opções etc. Essas características podem trazer implicações na produção, consequentemente, à inclusão ou sua omissão causa um impacto nos custos e, eventualmente, no custo do ciclo de vida.

Outro motivo para utilizar o CBC é que as mesmas características aparecem em muitas partes diferentes do objeto; então, podem ser usadas frequentemente as informações comparativamente de custo para uma classe de características. Além disso, o pessoal de produção tem numerosos dados geométricos passados que podem ser relacionados às características. Outra vantagem na utilização do custeio baseado em características é que este proporciona ao projetista uma poderosa ferramenta para visualizar a relação entre custos e o desenvolvimento dos aspectos do design que podem influenciar em diferentes pontos como, preço, qualidade, tempo de ciclo, entre outros.

Desta forma, os gestores podem utilizar informações das características para a prevenção pró-ativa de custos. As áreas de pesquisa e desenvolvimento podem construir formas detalhadas pelo uso das características. Assim, podem avaliar as características em relação à facilidade ou dificuldade de produção, tempo de execução, entre outras. Também podem desenvolver objetos tendo em mente suas características como, funcionalidade, desempenho, preço, qualidade etc.

O CBC pode auxiliar na melhor compreensão dos fatores que causam a variação do processo, o que permite melhorias no processo e no objeto. Ele visa identificar a 
variação do processo causada por exigências ou condições (características) dos objetos. Assim, o CBC identifica o problema específico que causa a variação e, esse conhecimento das características habilita a organização a entender e minimizar a variação, tornando o resultado mais previsível e os custos controláveis.

Os valores determinados podem ser utilizados como medidas-padrão no processo orçamentário, facilitando o controle dos custos; como também, direcionada a organização a atingir os resultados planejados.

A definição de custos por características é extremamente importante na tomada de inúmeras decisões, como a definição do preço de venda de cada item, projetos de engenharia e design, entre outras. Já que o sistema possibilita formar o preço a partir da característica. Com o custo por característica, a empresa pode determinar preços diferentes para seus produtos. Isto sem deixar de atender os desejos e as necessidades dos clientes por produtos e serviços personalizados. Consequentemente, ele apóia e é essencial na aproximação e no alinhamento dos interesses da empresa com as necessidades dos clientes. Portanto, esse sistema aproxima a empresa da realidade do mercado, que é a venda cada vez maior de produtos personalizados.

O CBC pode auxiliar a empresa a buscar soluções que atendam às necessidades dos clientes, modificando as especificações dos objetos. O sistema é compatível com a filosofia de atendimento as necessidades dos consumidores.

A aplicação do custeio por características amplia as fronteiras do conhecimento sobre os custos e suas variações, ajudando a empresa a tornar-se mais eficiente. Como também auxilia a abordar os clientes de forma individualizada, com a customização e personalização dos objetos, criando um relacionamento duradouro e lucrativo. 


\section{LIMITAÇÕES DO CBC}

Embora o CBC tenha inúmeras vantagens, ele também apresenta limitações. Não há nenhum consenso amplamente aceito que uma característica da empresa será idêntica em outra.

Cada empresa terá que determinar suas próprias características. O que pode ser uma característica a uma empresa não necessariamente será em outra, em função de inúmeros fatores como, tipo de produto, tecnologia, processos e atividades, entre outros; o que torna o modelo único para cada organização.

O CBC não elimina por completo o Custeio Baseado em Atividades - $A B C$ ou outro método, ao contrário ambos se complementam. As bases conceituais do $A B C$ dão sustentabilidade ao custeio baseado em características. Outro aspecto também a ressaltar, é que este sistema não resolve totalmente o problema da alocação dos custos indiretos.

\section{CONSIDERAÇÕES FINAIS}

O custeio baseado em características vem ao encontro das necessidades atuais de inúmeras empresas, pois facilita a determinação dos custos dos objetos com diferentes características. Conforme descrito anteriormente, ele pode ser utilizado de forma pró-ativa na gestão de custos. Isto decorre da possibilidade dos projetistas desenvolver formas de amenizar a variação das diferentes características no processo de produção.

Ele também pode ser extremamente útil na formação do preço de venda $e$, como, este geralmente é determinado a partir do custo, há a possibilidade de formação de preços diferenciados dependendo da característica escolhida pelo cliente.

Diante das informações de custo das características, a empresa pode oferecer produtos e serviços com várias configurações, atendendo melhor as necessidades de seus clientes. Além, desse conhecimento maior das variações, possibilitar oferecer maior número de características ao menor custo possível. 
O Uso do Custom-Made Based Costing-CBC no Custeamento das Características de Produtos e

Esse sistema exige a participação de todos às forças da empresa e um planejamento centrado na proposição de valor. Isto porque, demanda novas linhas de características e produtos, novos processos, demandas, sistemas e informações para seu gerenciamento e principalmente nova cultura empresarial. Antes de implementar qualquer mudança relacionada às características, a empresa precisa assimilar primeiro a dinâmica do mercado e a ela adaptar sua estratégica.

\section{REFERÊNCIAS}

BRIMSON, James A. Contabilidade por Atividades: Uma Abordagem de Custeio Baseado em Atividade. São Paulo: Atlas, 1996.

BRIMSON, James A., ANTOS, John. Driving Value Using Activity-Based Budgeting. New York: Wiley, 1999.

BRIMSON, James A. Conceitos Avançados de Gestão da Cadeia de Valor - Value Stream Management. São Paulo, 2000.

FILOMENA, Tiago Pascoal, KLIEMANN NETO, Francisco José. Modelo de Gestão de Custos para o Desenvolvimento de Produto. Punta del Este: Anais do VII Congreso del Instituto Internacional de Costos, 2003.

HILTON, Ronald W., MAHER, Michael W., SELTO, Frank H. Cost Management: Strategies for Business Decision. New York: Irwin McGraw-Hill, 2000.

HORNGREN, Charles T., FOSTER, George, DATAR, Krikant M. Contabilidade de Custos. 9ª. Ed. Rio de Janeiro: LTC, 1997.

JACKSON, Steve, SAWYERS, Roby. Managerial Accounting: A focus on Decision Making. Orlando: Harcourt College Publishers, 2001.

MACRAE, Hamish. O Mundo em 2020. São Paulo: Revista HSM Management. N.13, jul.-ago./1999.

MASKELL, Brian H., BAGGALEY, Bruce. Lean Management Accounting, New Jersey: BMA Inc, 2004. Site: www.maskell.com/.

TURNEY, Peter B.B. Common Cents: The ABC Performance Breakthrough. Hillsboro: Cost Technology, 1993. 
O Uso do Custom-Made Based Costing-CBC no Custeamento das Características de Produtos e

WEYGANDT, Jerry J., KIESO, Donald E., KIMMER, Paul D. Managerial Accounting Tools for Business Decision Making. 2a Ed. New York: John Wiley, 2002.

ZIMMERMAN, Jerold L. Accounting For Decision Making and Control. 3a.Ed. New York: Irwin MacGraw-Hill, 2000.

COOPER, Robin, SLAGMULDER, Regine. Redução de Custos com Inteligência. São Paulo: HSM Management, N.40, Set.-Out./2003.

KEARNEY, A. T. Três Idéias de Marketing. São Paulo: HSM Management, N.27, Jul.Ago./2001.

RAPP, Stan. Muitos para Um. São Paulo: HSM Management, N.17, Nov.-Dez./1999.

Rogers, Martha. 3 Tipos de Clientes, 3 Perfis de Empresas, 3 Famílias de Tecnologias e o CRM. São Paulo: HSM Management, No.36, Jan.-Fev/2003.

SEYBOLD, Patrícia B. A Revolução do Cliente - Como Prosperar com os Clientes no Controle. São Paulo: HSM Management, Book Summary 3, 2002.

SHANK, John. O Custo Focado no Cliente. São Paulo: HSM Management, N.19, Mar.Abr./2000.

TSENG, Mitchell M, PILLER, Frank T. The Customer Centric Enterprise: Advances in mass customization and personalization. Heidelberg: Springer, 2003. 